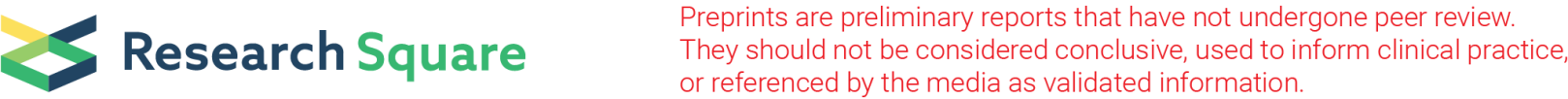

\section{Conjoined versus separate technique: a meta- analysis of anastomosis techniques for urinary diversion after bladder cancer}

\section{Liu Daqian}

Affiliated Hospital of Medical College Qingdao University

\section{Wang Yonghua}

Affiliated Hospital of Medical College Qingdao University

Zhao Yang

Affiliated Hospital of Medical College Qingdao University

Yang Xuecheng

Affiliated Hospital of Medical College Qingdao University

wang xinsheng ( $\nabla$ wxsheng@163.com )

Affiliated Hospital of Medical College Qingdao University https://orcid.org/0000-0002-4642-690X

Niu Haitao

Affiliated Hospital of Medical College Qingdao University

Research article

Keywords: anastomosis, urinary diversion, bladder cancer, radical cystectomy

Posted Date: July 9th, 2019

DOl: https://doi.org/10.21203/rs.2.11111/v1

License: (1) This work is licensed under a Creative Commons Attribution 4.0 International License.

Read Full License 


\section{Abstract}

Introduction: This was a meta-analysis of studies on conjoined and separate anastomosis for urinary diversion after radical cystectomy due to bladder cancer. Methods: We searched databases (PubMed, Embase and the Cochrane Central Register of Controlled Trials) for studies regarding anastomosis for urinary diversion due to bladder cancer. The meta-analysis was designed to determine the difference between conjoined and separate anastomosis. Six studies including 1601 patients were considered in the meta-analysis (654 in the separate group and 947 in the conjoined group). Results: There were no significant differences with respect to age, gender or duration of follow-up. There were seven studies that compared the rate of stricture and the rate of hydronephrosis. For overall stricture, there were 186 of 1163 ureters in the separate group and 64 of 1718 ureters in the conjoined group (odds ratio, 4.53; 95\% Cl, 2.01$10.22 ; \mathrm{P}=0.0003$ ). For overall hydronephrosis patients, there were 55 of 205 ureters in the separate group and 51 of 254 ureters in the conjoined group (odds ratio, 1.48; $95 \% \mathrm{Cl}, 0.95-2.29 ; \mathrm{P}=0.08$ ). Conclusion: The separate anastomosis had a higher ratio of strictures than did the conjoined group. The separate anastomosis group experienced hydronephrosis more often than did the conjoined anastomosis group. The separate anastomosis is the better choice for surgery during the operation.

\section{Background}

Bladder cancer is a common malignant tumor of the urinary bladder. Radical resection may be invasive or confined to the bladder muscle layer for recurrent bladder cancer[1]. Urinary diversion for radical cystectomy is one of the most complicated operations in urology. It has the characteristics of large trauma, complicated operation, long operation time and many postoperative complications. With the continuous improvement of surgical methods in recent years, it has become the gold standard for invasive bladder cancer. Muscle invasive bladder cancer of T2 4aロNO X $\square \mathrm{M} 0$, high-risk non-muscle invasive bladder cancer(NMIBC), BCG-ineffective carcinoma in situ and recurrent non-muscle invasive bladder cancer all should be underwent radical cystectomy. Urinary diversion after bladder cancer refers to ileal conduit surgery and the ileal orthotopic neobladder technique, among others. There are several ways to perform ureteral anastomosis, including reflux and anti-reflux anastomoses with colonic or intestinal anastomosis. Anastomosis techniques can also be broadly divided into two groups: the separate group and the conjoined group.

The separate anastomosis technique, initially described in the early 1950s, involves anastomosing each ureter to the bowel segment separately[2]. This includes Bricker anastomosis and LeDuc technique. In the conjoined anastomosis technique, both ureters are cut to the same length, then the medial walls are joined and the free edges of the newly conjoined ureters are anastomosed to the proximal end of an open bowel segment[3]. This technique includes the Wallace anastomosis.

The selection of the technique for anastomosis depends on surgeon preference and patient characteristics. There are disadvantages to both techniques. The disadvantage of separate anastomosis 
is the higher rate of stricture[4], while the disadvantages of conjoined anastomosis are obstruction and tumor recurrence[5].

We performed a meta-analysis to compare the incidence of hydronephrosis and ureteral stricture between the separate anastomosis and conjoined anastomosis in order to determine the efficacy of the two surgical methods.

\section{Methods}

\section{Study design}

Systematic review of randomized controlled trials(RCTs) was carried out using the referred reporting items for systematic reviews and meta-analyses(PRISMA) checklist[6].

\section{Identification of Studies}

We searched PubMed, Embase and the Cochrane Central Register of Controlled Trials by entering the following in the search algorithm: (anastomosis) AND (bladder cancer) AND (cystectomy) OR (urinary diversion). We set English as the language restriction. We examined the titles and the abstracts, and then we obtained the trials for further examination.

\section{Eligibility criteria}

Studies with comparative data between separate and conjoined ureteral anastomosis were eligible for inclusion. The subjects of the studies were sufficient and the two groups were matched with rigorous controls. Randomized and nonrandomized trials and prospective and retrospective trials were all examined. Exclusion criteria included articles not consistent with the review, animal experiments, pathological reports, subjects obviously not consistent with single anastomosis, and absence of comparison.

\section{Quality assessment}

The Jadad Scale was used to assess the quality of each RCT[7]. Two authors assessed the selected publications. We assessed the patient allocation method, blinding methods, concealment of allocation procedures, reporting, and other factors according to Cochrane Library recommendations. Then, the studies were qualitatively classified according to the guidelines presented in the Cochrane Handbook for Systematic Reviews of Interventions (version 5.1.0)[8]. The study was evaluated and classified based on quality assessment criteria: (A) Satisfying almost all of the quality criteria, and it should be considered to have a low probability of bias; (B) Ambiguous about one or more quality criteria and had a moderate risk of bias; or (C) Barely met the quality criteria, the study was considered to have a high probability of bias. All authors articipated in the quality assessment of RCTs retrieved, eventually everyone agree with the results of the assessment. All studies were evaluated using quality categories by assessing the criteria of the quality and grading the risk of bias. Discrepancies were resolved by consensus. 
We recorded the following information regarding each eligible trial: authors' names, year of publication, study type, length of follow-up, total number of patients, technique of ureteral anastomosis, complication and the number of patients.

\section{Statistical analysis}

The meta-analysis was conducted using RevMan v.5.1.0 (Cochrane Collaboration, Oxford, UK)[9]. For anastomosis in each study, we estimated the odds ratio (OR) with its variance and $95 \%$ confidence interval $(\mathrm{Cl})$. The random effects analysis weighted the natural logarithm of each study's OR by the inverse of its variance plus an estimate of the between-study variance in the presence of between-study heterogeneity. The heterogeneity between ORs for the same outcome between different studies was assessed. This was done through the use of the 12 inconsistency test and chi-square-based Cochran's Q statistic test[10]. The $p$ value was two-tailed and was considered to be statistically significant when $p<0.10$. The $I 2$ inconsistency test was used to evaluate heterogeneity between studies in which $12>50 \%$ indicate high heterogeneity, and I2> 75\% indicate higher heterogeneity.

\section{Results}

\section{Characteristics of the individual studies}

There were six eligible studies containing data comparing separate and conjoined ureteral anastomosis (Table 1). We identified 215 potentially eligible studies, and 165 studies were excluded by not comparing separate and conjoined anastomosis, and 44 articles were excluded due to lack of useful data. The flow chart in Fig. 1 describes the selection process. All studies were published in English. All patients underwent urinary diversion after radical cystectomy for bladder cancer. These were all retrospective trials.

Table 1

Fig. 1

\section{Quality of the individual studies}

The six studies were cohort studies. The surgical methods were all compared and patient data were all collected retrospectively. The quality of all identified studies was categorized as A or B, though the final Jadad score for each study was low (Table 2), all studies were included in the analysis.

Table 2

Patient demographics 
There were 1587 patients in the stricture group, and there were 2881 ureters in all (Fig. 2). The 1163 separate anastomosis ureters included 186 which developed stricture (16.0\%), and 1718 conjoined anastomosis ureters had 64 strictures (3.7\%). The overall stricture rate for all ureters in this group was 250 of 2881 ureters (odds ratio, $4.53 ; 95 \% \mathrm{Cl}, 2.01-10.22 ; \mathrm{P}=0.0003$ ).

Fig. 2

There were 363 patients in the hydronephrosis group, and there were 459 ureters in all (Fig. 3). There were 55 ureters which developed hydronephrosis of the 205 separate anastomosis ureters $(26.8 \%)$, and there were 51 ureters which developed the hydronephrosis of the 254 conjoined anastomosis ureters (16.9\%). The overall hydronephrosis rate for all ureters in this group was 106 of 459 (odds ratio, $1.48 ; 95 \% \mathrm{Cl}, 0.95$ $2.29 ; \mathrm{P}=0.08)$.

Fig. 3

\section{Publication bias}

We performed a qualitative estimation of publication bias of the studies using two funnel plots (Fig. $4,5)$. Both values of hydronephrosis and stricture lay within the scope of the funnel plots and were evenly distributed on both sides of the central lines, suggesting no evidence of bias.

Fig. 4

Fig. 5

\section{Discussion}

There is high malignancy, recurrence and distant metastasis in the invasive bladder cancer. The current standard of treatment is still the radical cystectomy combined with urinary diversion, and its surgical procedure is complicated, also there is a high incidence of postoperative complications[16]. The anastomosis of the ureteral stump and free ileal intestinal fistula is the key technical points of the operation, which directly determines the incidence of the ureter stricture and the postoperative hydronerhrosis.

Through our meta-analysis, we found that the rates of stricture and hydronephrosis in the separate group were higher than those of the conjoined anastomosis group. And there was no heterogeneity on the basis of the chi-square-based Cochran's $Q$ statistic test[10], in which $p<0.1$. Stricture is a serious postoperative problem, and the conjoined anastomosis has a lower incidence than the separate anastomosis.

Therefore, it become a common technique to handle ureteroileal anastomotic strictures and hydronephrosis $[17,18]$. The separate technique requires a surgical closure technique for the end of the ileum in addition to the ureteroileal anastomosis, while the two ureters are combined and connected to the end of the afferent limb by the end-to-end method in the conjoined anastomosis, therefore, there is low rate of stricture complications in neobladder reconstructions[12]. 
There was no heterogeneity in the hydronephrosis group according to our meta-analysis, and the overall rate of hydronephrosis was $23.1 \%$. The hydronephrosis rate of conjoined anastomosis as lower that of the separate anastomosis. The separate anastomosis requires the left ureter to travel to the right through the posterior sigmoid mesenteric approach, thus causing compression of the left ureter; while the left ureter needs to travel to the right and anastomosis with the intestinal fistula, which will lead to excessive ureteral distraction, excessive tension, resulting in ischemic stenosis of the left ureter. Studies have shown that the separate anastomosis can lead to postoperative complications due to changes in the anatomical position of the ureter, and it occurs mostly in the ureteral anastomosis[19].

The separate and conjoined anastomosis procedures are the most common techniques used for urinary diversion after bladder cancer[20]. Both techniques have some limitations. The separate technique has a higher rate of stricture and hydronephrosis, with a possibility of upper urinary tract recurrence[21]. Surgeons choose the anastomosis depending on patient characteristics. The limitations of early studies include the lack of classification of complications of the two anastomosis, and there is little data comparison in the early studies[22].

The incidence of complication of conjoined anastomosis is low, which can lead to recurrence of the upper urinary tract tumor and block both ureters, causing uremia from bilateral obstruction[5]. There are several risk factors for upper urinary tract recurrence, including prostatic urethra involvement, ureteral involvement or positive ureteral margin, and recurrent tumor[23]. Therefore, the conjoined technique is not used for patients with recurrent tumor or carcinoma of the ureters[24].

Surgeons choose different techniques according to different situations. Ureteral length after retrosigmoidal tunneling is a factor influencing the choice of anastomosis technique. The conjoined technique is better when the ureteral length is similar on both sides, while the separate technique is preferred when lengths are disparate.

Admittedly, there were also some limitations to our study. First the number of studies included was small: only six studies compared the two types of anastomosis, and there were few randomized trials, therefore clinical heterogeneity was inevitable. Second, the impact of unpublished research was not considered, therefore, there might be some publication bias or selection bias. Third, there are other complications

after surgery that were not included in our analysis. Meanwhile, the number of patients was low, introducing possible search bias.

\section{Conclusions}

The effect of surgical methods on the quality of life after surgery is increasingly a concern of urological surgeons[25]. If we want reduce the rate of stricture and hydronephrosis, we can choose conjoined anastomosis. Surgeons should choose the technique according to patients' characteristics.

\section{List Of Abbreviations}


OR: Odds ratio; RCTs: Randomized controlled trials; NMIBC: non-muscle invasive bladder cancer; Cl: Confidence interval; BCG: Bacillus Calmette-Guerin; PRISMA: Preferred reporting items for systematic reviews and meta-analyses.

\section{Declarations}

\section{Ethics approval and consent to participate}

Not applicable.

\section{Consent for publication}

Not applicable.

\section{Availability of data and materials}

All data and materials in this study are included in this published article.

\section{Competing interests}

There is no competing interests in any authors.

\section{Funding}

This study was financially supported by the National Natural Science Foundations of China (81401899, 81472411, 81772713, 81372752, 81672662); Taishan Scholar Program of Shandong Province (tsqn20161077); China Postdoctoral Science Foundation (2017M622144) and Qingdao Postdoctoral Application Research Project; Qingdao Young Scientist Applied Basic Research Fund (15-9-1-51-jch, 16-62-28-NSH); Natural Science Foundation (ZR2014HM088, ZR2014CM040), Key Research and Development Program of Shandong Province (2017GSF18193) and the Science and Technology Development Foundation (2014GHY115025) of Shandong Province.

\section{Authors' Contributions}

LDQ, and WYH collected the studies, analysed statistics and drafted the manuscript. YXC and ZY helped to extract the data. NHT and WXS designed the study and edited the manuscript. LDQ and WYH Contributed equally._All authors have read and approved the manuscript.

\section{Acknowledgements}

Not applicable.

\section{Author details}

1 Department of Urology, Affiliated Hospital of Qingdao University, Qingdao, Shandong, P.R. China; 
2 Key Laboratory of Urinary System Diseases, Qingdao, Shandong, P.R. China;

*Equal contributors

Corresponding Author: Niu Haitao and Wang Xinsheng

\section{References}

1. Nieuwenhuijzen JA, de Vries RR, Bex A, van der Poel HG, Meinhardt W, Antonini N, Horenblas S: Urinary diversions after cystectomy: the association of clinical factors, complications and functional results of four different diversions. European urology 2008, 53(4):834-842; discussion 842-834.

2. Butcher HR, Jr., Sugg WL, Mc AC, Bricker EM: lleal conduit method of ureteral urinary diversion. Annals of surgery 1962, 156:682-691.

3. Wallace DM: Uretero-ileostomy. British journal of urology 1970, 42(5):529-534.

4. Kouba E, Sands M, Lentz A, Wallen E, Pruthi RS: A comparison of the Bricker versus Wallace ureteroileal anastomosis in patients undergoing urinary diversion for bladder cancer. The Journal of urology 2007, 178(3 Pt 1):945-948; discussion 948-949.

5. Evangelidis A, Lee EK, Karellas ME, Thrasher JB, Holzbeierlein JM: Evaluation of ureterointestinal anastomosis: Wallace vs Bricker. The Journal of urology 2006, 175(5):1755-1758; discussion 1758.

6. Moher D, Liberati A, Tetzlaff J, Altman DG, Group P: Preferred reporting items for systematic reviews and meta-analyses: the PRISMA statement. Bmj 2009, 339:b2535.

7. Jadad AR: Asking Patients to Write Lists - Randomized Controlled Trials Support It. British medical journal 1995, 311(7007):746-746.

8. Cochrane Handbook for Systematic Reviews of Interventions. Online Kensaku 2014, 35(3):154-155.

9. DerSimonian R: Meta-analysis in the design and monitoring of clinical trials. Stat Med 1996, 15(12):1237-1248.

10. Lau J, loannidis JP, Schmid CH: Quantitative synthesis in systematic reviews. Annals of internal medicine 1997, 127(9):820-826.

11. Liu L, Chen M, Li Y, Wang L, Qi F, Dun J, Chen J, Zu X, Qi L: Technique selection of bricker or wallace ureteroileal anastomosis in ileal conduit urinary diversion: a strategy based on patient characteristics. Annals of surgical oncology 2014, 21(8):2808-2812.

12. Shigemura K, Yamanaka N, Imanishi O, Yamashita M: Wallace direct versus anti-reflux Le Duc ureteroileal anastomosis: comparative analysis in modified Studer orthotopic neobladder reconstruction. 
International journal of urology : official journal of the Japanese Urological Association 2012, 19(1):4953.

13. Delaume A, Vedrine N, Guandalino M, Mulliez A, Bruyere F, Boiteux JP, Guy L: [Comparison Bricker's and Wallace's anastomoses in ileal conduit: Retrospective, multicenter study]. Progres en urologie: journal de l'Association francaise d'urologie et de la Societe francaise d'urologie 2016, 26(1):58-64.

14. Hautmann RE, de Petriconi R, Kahlmeyer A, Enders M, Volkmer B: Preoperatively Dilated Ureters are a Specific Risk Factor for the Development of Ureteroenteric Strictures after Open Radical Cystectomy and Ileal Neobladder. The Journal of urology 2017, 198(5):1098-1106.

15. Desai MM, Gill IS, de Castro Abreu AL, Hosseini A, Nyberg T, Adding C, Laurin O, Collins J, Miranda G, Goh AC et al: Robotic intracorporeal orthotopic neobladder during radical cystectomy in 132 patients. The Journal of urology 2014, 192(6):1734-1740.

16. Hautmann RE, Gschwend JE, de Petriconi RC, Kron M, Volkmer BG: Cystectomy for transitional cell carcinoma of the bladder: results of a surgery only series in the neobladder era. The Journal of urology 2006, 176(2):486-492; discussion 491-482.

17. Wallace DM: Ureteric diversion using a conduit: a simplified technique. British journal of urology 1966, 38(5):522-527.

18. Linke CA, Rashid HA, Davis RS, Fridd CW: Wallace method of ureteroileal anastomosis. Urology 1975, 6(1):43-47.

19. Konety BR, Allareddy $\mathrm{V}$, Herr $\mathrm{H}$ : Complications after radical cystectomy: analysis of population-based data. Urology 2006, 68(1):58-64.

20. Bricker EM: Bladder substitution after pelvic evisceration. 1950. The Journal of urology 2002, 167(2 Pt 2):1140-1145; discussion 1146.

21. Davis NF, Burke JP, McDermott T, Flynn R, Manecksha RP, Thornhill JA: Bricker versus Wallace anastomosis: A meta-analysis of ureteroenteric stricture rates after ileal conduit urinary diversion. Canadian Urological Association journal = Journal de l'Association des urologues du Canada 2015, 9(56):E284-290.

22. Yang WJ, Cho KS, Rha KH, Lee HY, Chung BH, Hong SJ, Yang SC, Choi YD: Long-term effects of ileal conduit urinary diversion on upper urinary tract in bladder cancer. Urology 2006, 68(2):324-327.

23. Picozzi S, Ricci C, Gaeta M, Ratti D, Macchi A, Casellato S, Bozzini G, Carmignani L: Upper urinary tract recurrence following radical cystectomy for bladder cancer: a meta-analysis on 13,185 patients. The Journal of urology 2012, 188(6):2046-2054.

24. Dahl DM, Mcdougal WS: Use of intestinal segments in urinary diversion. 2003. 
25. Gerharz EW, Mansson A, Mansson W: Quality of life in patients with bladder cancer. Urologic oncology 2005, 23(3):201-207.

\section{Tables}

Table 1

\begin{tabular}{l|l|l|l|l|l|}
\hline & Anastomosis & $\begin{array}{l}\text { Total/ } \\
\text { Available }\end{array}$ & complication & $\begin{array}{l}\text { Lesion } \\
\text { ureters/ } \\
\text { Separate } \\
\text { ureters }\end{array}$ & $\begin{array}{l}\text { Lesion ureters/ } \\
\text { Conjoined ureters }\end{array}$ \\
\hline J & $\begin{array}{l}\text { Bricker/ } \\
\text { Wallace } \\
\text { anastomosis }\end{array}$ & $99 / 99$ & stricture & $8 / 106$ & $4 / 92$ \\
\hline $\begin{array}{l}\text { LeDuc technique/ } \\
\text { Wallace }\end{array}$ & $72 / 71$ & $\begin{array}{l}\text { Hydronephrosis/ } \\
\text { stricture }\end{array}$ & $\begin{array}{l}12 / 64 \\
9 / 64\end{array}$ & $\begin{array}{l}7 / 78 \\
0 / 78\end{array}$ \\
\hline B & $\begin{array}{l}\text { Bricker } \\
\text { Wallace } \\
\text { anastomosis }\end{array}$ & $186 / 186$ & stricture & $7 / 187$ & $0 / 184$ \\
\hline $\begin{array}{l}\text { Wricker/ } \\
\text { Wallace }\end{array}$ & $190 / 160$ & Hydronephrosis & $43 / 141$ & $43 / 176$ \\
\hline In & $\begin{array}{l}\text { LeDuc technique/ } \\
\text { Wallace }\end{array}$ & $953 / 953$ & Stricture & $158 / 714$ & $56 / 1192$ \\
\hline & $\begin{array}{l}\text { Bricker/ } \\
\text { Wallace } \\
\text { anastomosis }\end{array}$ & $136 / 132$ & stricture & $4 / 92$ & $6 / 172$ \\
\hline
\end{tabular}

Table 2 


\begin{tabular}{|c|c|c|c|c|c|c|}
\hline \begin{tabular}{|l|} 
Allocation \\
sequence \\
generation
\end{tabular} & $\begin{array}{l}\text { Allocation } \\
\text { concealment }\end{array}$ & Blinding & $\begin{array}{l}\text { Calculation } \\
\text { of sample } \\
\text { size }\end{array}$ & $\begin{array}{l}\text { Statistical } \\
\text { analysis }\end{array}$ & $\begin{array}{l}\text { Level } \\
\text { of } \\
\text { quality }\end{array}$ & $\begin{array}{l}\text { Jadad } \\
\text { Score } \\
\text { (5- } \\
\text { point) }\end{array}$ \\
\hline $\mathrm{A}$ & B & $B$ & YES & $\begin{array}{l}\text { Student's } \\
\text { t-test }\end{array}$ & $\mathrm{B}$ & 3 \\
\hline $\mathrm{A}$ & B & $B$ & YES & $\begin{array}{l}\text { Student's } \\
\text { t-test }\end{array}$ & $\mathrm{A}$ & 4 \\
\hline B & B & B & YES & $\begin{array}{l}\text { Student's } \\
\text { t-test }\end{array}$ & $\mathrm{A}$ & 4 \\
\hline $\mathrm{A}$ & $\mathrm{A}$ & $\mathrm{B}$ & YES & $\begin{array}{l}\text { Student's } \\
\text { t-test }\end{array}$ & $\mathrm{B}$ & 3 \\
\hline $\mathrm{B}$ & $\mathrm{A}$ & B & YES & $\begin{array}{l}\text { Student's } \\
\text { t-test }\end{array}$ & $\mathrm{B}$ & 3 \\
\hline B & $\mathrm{A}$ & B & $\overline{\text { YES }}$ & $\begin{array}{l}\text { Student's } \\
\text { t-test }\end{array}$ & $\mathrm{A}$ & 4 \\
\hline
\end{tabular}

Figures 


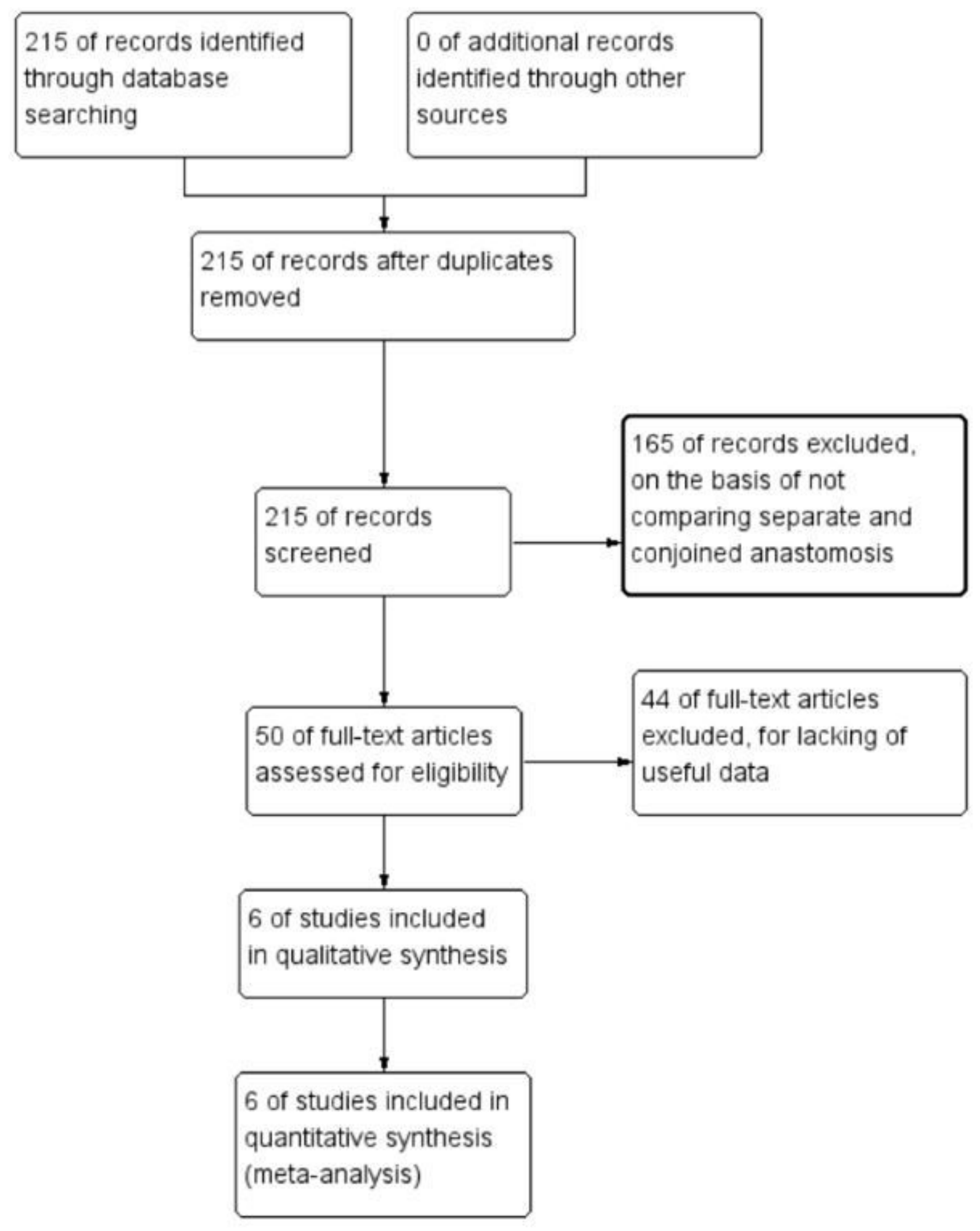

Figure 1

A flow diagram of the study selection process. 


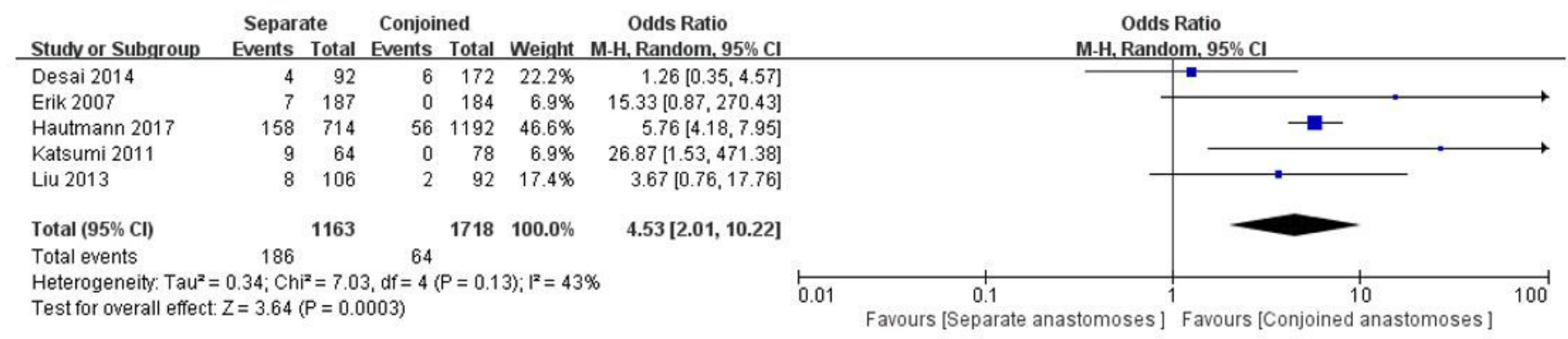

Figure 2

Forest plots showing differences of two techniques. $\mathrm{M}-\mathrm{H}$ : mantel haenszel, $\mathrm{Cl}$ : confidence interval

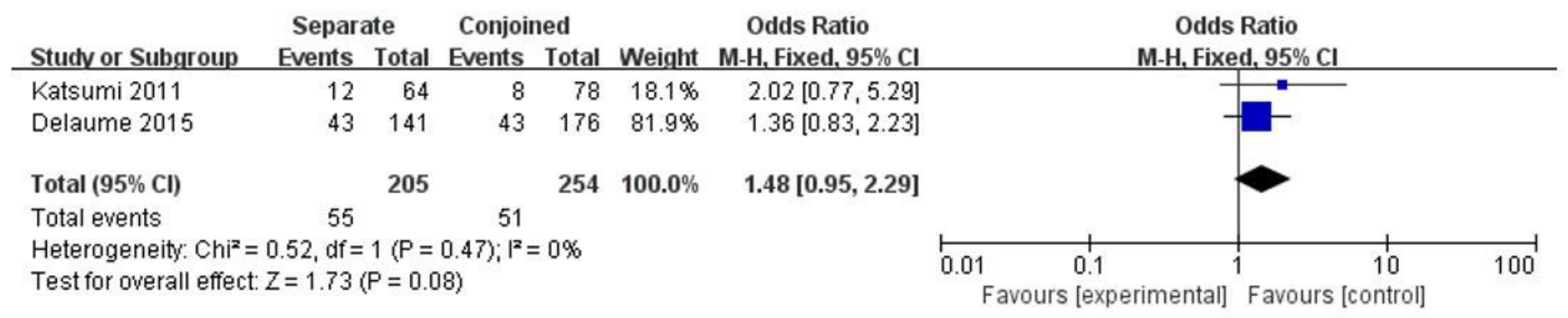

\section{Figure 3}

Forest plots showing differences of two techniques. $\mathrm{M}-\mathrm{H}$ : mantel haenszel, $\mathrm{Cl}$ : confidence interval 


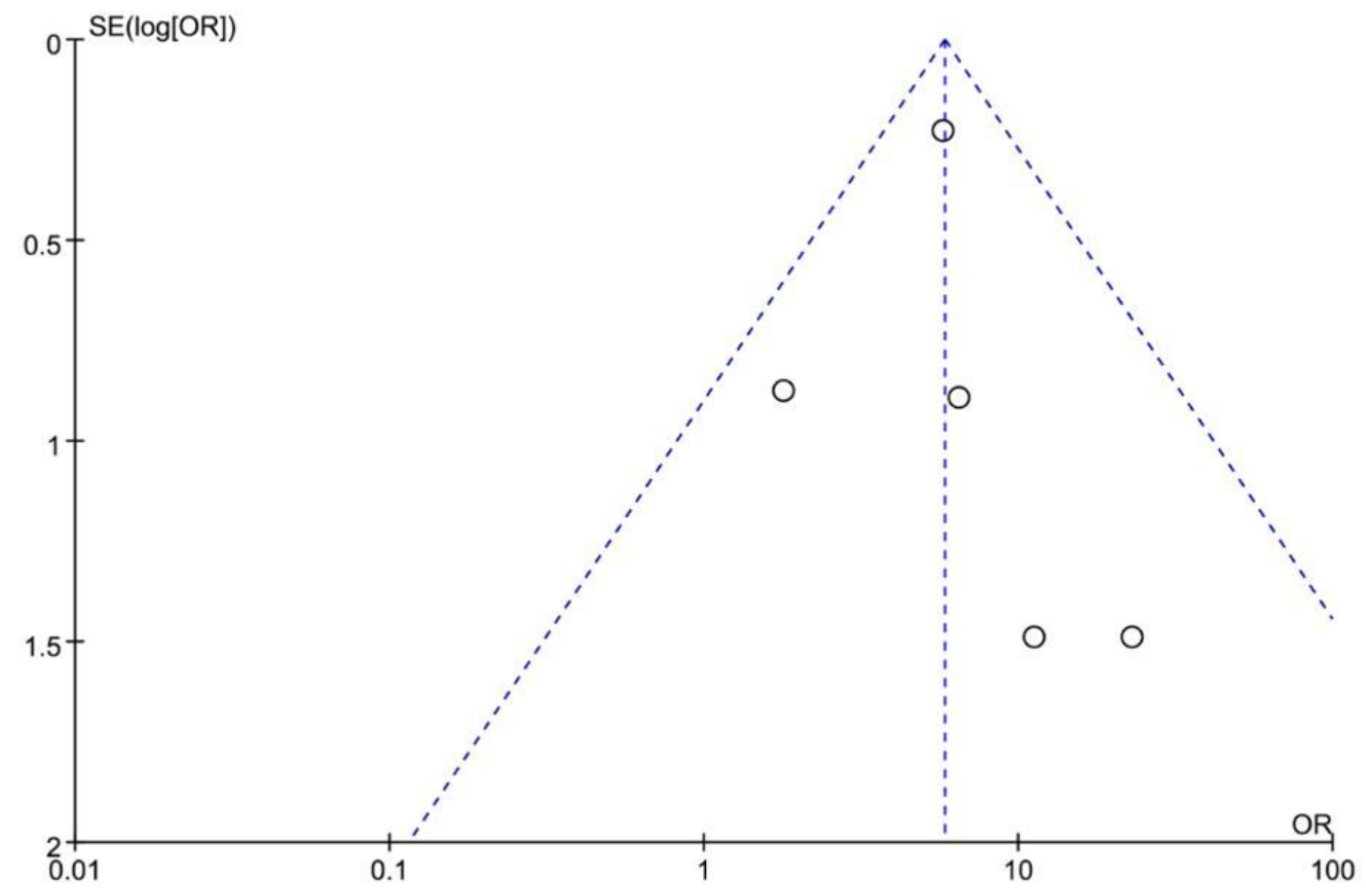

Figure 4

Funnel plot of the stricture complication in our meta-analysis. OR: odds ratio, SE: standard error 


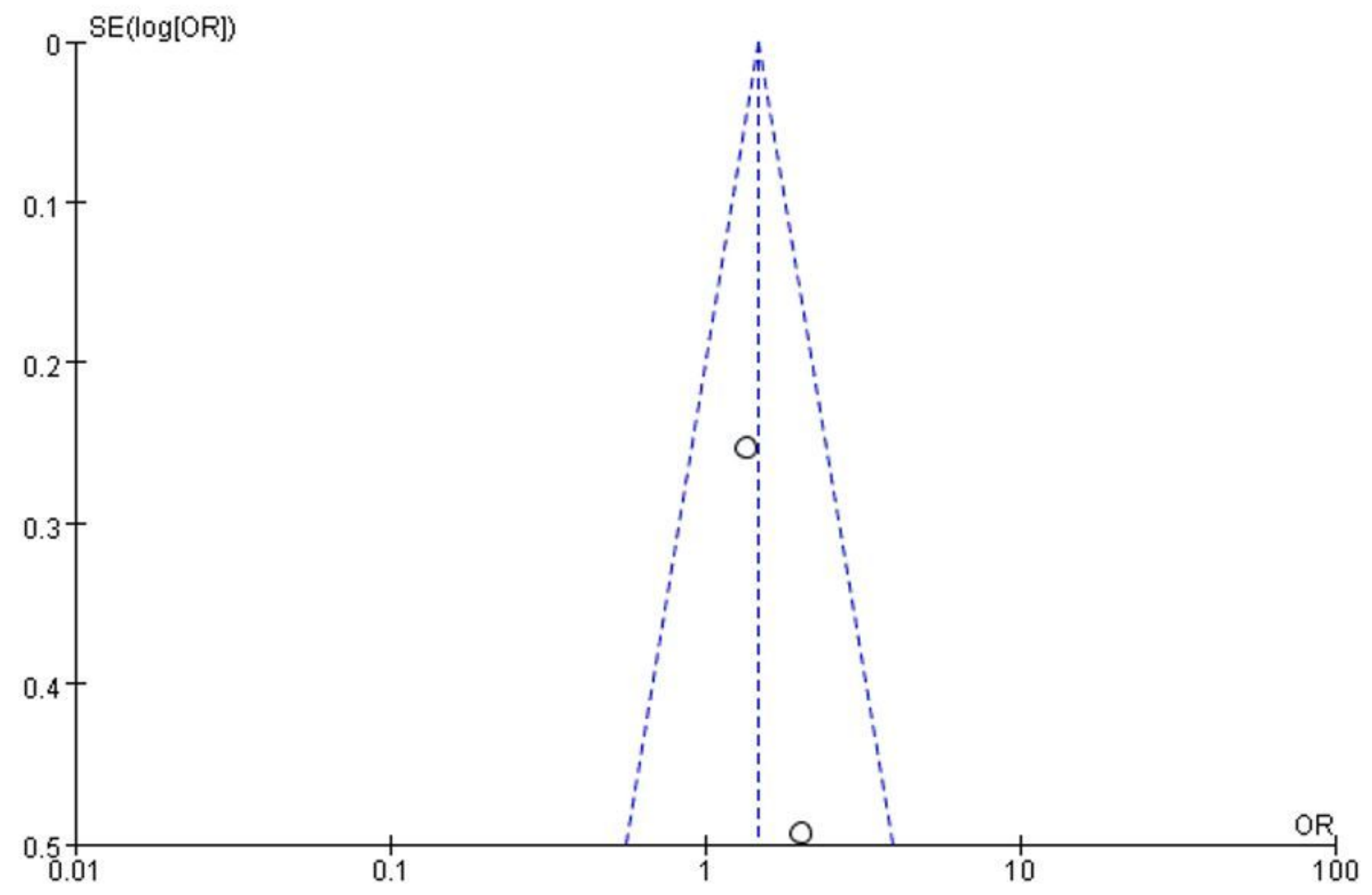

Figure 5

Funnel plot of the hydronephrosis complication in our meta-analysis. OR: odds ratio, SE: standard error 